Brit. J. vener. Dis. (1961), 37, 158.

\title{
A COMPARISON OF SENSITIVITY TO PENICILLIN OF N. GONORRHOEAE, 1960 AND 1958*
}

BY

\author{
E. H. LETCHNER AND C. S. NICOL \\ St. Thomas's Hospital, London
}

A series of sensitivity tests carried out by CradockWatson, Shooter, and Nicol (1958), showed that about 19 per cent. of strains of $N$. gonorrhoeae isolated at that time were resistant to $0 \cdot 12$ units $/ \mathrm{ml}$. penicillin. It was largely for this reason that the dosage employed before 1958 (300,000 units administered at one injection) was doubled to 600,000 units procaine penicillin and has been continued to the present time. Because the incidence of gonorrhoea has been increasing during the past few years it has become important to determine whether the sensitivity to penicillin of $N$. gonorrhoeae was changing.

\section{Methods}

In order to assess the position to-day, cultures were obtained from all male patients attending the clinic at St. Thomas's Hospital during January, February, and March, 1960, and for a further 3 months cultures were obtained only from cases of relapsing gonorrhoea. The sensitivity of the strains so obtained was tested by the same methods as those employed by Cradock-Watson and others (1958). All strains which failed to multiply on hydrocele chocolate agar plates containing 0.12 units $/ \mathrm{ml}$. or more penicillin were regarded as sensitive. The Oxford staphylococcus was employed as a control organism.

\section{Results}

Employing the method outlined by CradockWatson and others (1958), we found that during the period January to March, 1960, of 107 patients who were investigated, ten were found to be infected by insensitive strains. The fact that the proportion of insensitive strains was only about half that found by

* Paper read at the European Symposium of the I.U.V.D.T. at Cracow, Poland, in September, 1960.
Cradock-Watson and others 2 years earlier (Fig. 1) suggests that the increase in dosage of procaine penicillin to 600,000 units had tended to eliminate more of the sensitive strains from the population while the earlier dosage may have allowed more strains to develop resistance. Patients for the 1958 series were drawn from St. Bartholomew's and St. Thomas's Hospitals, whereas in 1960 they came only from the latter. We have no reason to suppose that this affected the results in any way.

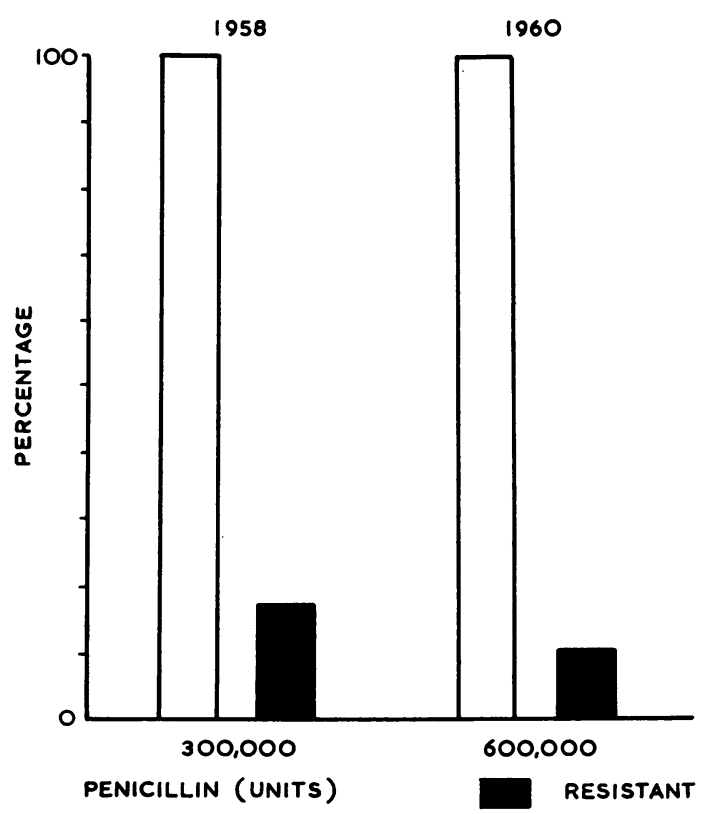

F1G. 1.-Percentage of strains resistant to penicillin in 1958 and 1960.

Nevertheless, it would seem that even a dosage so high as 600,000 units may not suffice, because there are indications that patients infected by an insensitive strain are more liable to relapse. Thus, of 100 
patients coming to the clinic from January to March, 1960 (all of whom received one injection of 600,000 units), no less than fifteen returned on a subsequent occasion.

The previous history of these patients was as follows:

Three patients suffering from acute gonorrhoea caused by insensitive strains formed part of a group of eight whose strains when tested at the first visit were insensitive. Three relapsed and all three strains were again found to be insensitive.

In a group of 92 patients whose strains had been sensitive at the first visit, twelve patients returned; only four of these were tested again but all were sensitive.

Although the data are incomplete, the results suggest that infection by an insensitive strain may not be controlled by the standard dosage of penicillin employed. The fact that, in the first series, three (38 per cent.) of the eight patients whose strains were insensitive returned, whereas twelve (13 per cent.) of the 92 bearing sensitive strains returned supports this suggestion.

This is to some extent confirmed by further investigations carried out during April, May, and June, 1960, on ten patients who returned to the clinic suffering from active gonorrhoea after having had the standard dosage of penicillin some time previously. From these, eight strains were isolated of which two were found to be insensitive.

It would thus appear probable that infection by certain strains of $N$. gonorrhoeae cannot be adequately controlled even by a dosage as high as 600,000 units of penicillin. Further confirmation of this was obtained by the behaviour of the disease in a young white male first seen in the clinic on May 19 whose subsequent history is as follows (Fig. 2):

May 19: Given 600,000 units procaine penicillin, gonococci present in smear.

May 20: No gonococci seen.

May 23: Gonococci seen and found to be insensitive to penicillin, 600,000 units procaine penicillin given.

May 24: Gonococci still present and found to be insensitive. $1 \mathrm{~g}$. oral penicillin given 4-hrly for 24 hrs.

May 27: Gonococci seen and still found to be insensitive. $1 \mathrm{~g}$. intramuscular streptomycin given and a 4-day course of $0.5 \mathrm{~g}$. sulphapyridosone commenced.

May 31: Gonococci still present in smear, still insensitive to penicillin and also found to be insensitive to streptomycin though sensitive to Achromycin. 5-day course of Achromycin, $250 \mathrm{mg}$. four times daily commenced.

\section{STREPTOMYCIN}

I g.

SULPHAMETHOXYPYRIDIAZINE

0.5 g. b.d. for 4 days 
All the strains isolated from the above patient were insensitive to penicillin. He did not return to the Clinic until much later when he reported that the treatment had cured him.

The patient stated that he had probably acquired the infection from a Negro woman in the West Indies, and he denied further exposure to risk during the course of treatment. It is therefore probable that this was a true relapse by a strain unusually resistant to both penicillin and streptomycin.

All the strains from this patient gave the typical fermentation reaction of $N$. gonorrhoeae and the sensitivity was kindly confirmed by Dr. A. E. W. Wilkinson at the London Hospital.

There is at present no evidence that the resistance patterns of the strains isolated in 1960 differed greatly from those isolated 2 years previously by Cradock-Watson and others, apart from a relative increase in the number of very sensitive strains. The relevant data are shown in the Table.

TABLE

INHIBITORY CONCENTRATIONS OF PENICILLIN

\begin{tabular}{c|c|c}
\hline $\begin{array}{c}\text { Minimum Inhibitory } \\
\text { Concentration } \\
\text { (units/ml.) }\end{array}$ & \multicolumn{2}{|c}{ Percentage Strains Inhibited } \\
\cline { 2 - 3 } & 1958 & 1960 \\
\hline $0.008-0.006$ & 5 & 44 \\
$0.016-0.012$ & 47 & 25 \\
$0.032-0.025$ & 23 & 15 \\
$0.06-0.05$ & 6 & 7 \\
0.12 & 9 & 4 \\
0.25 & 8 & 3 \\
0.51 & 3 & 1 \\
\hline
\end{tabular}

\section{Discussion}

The results suggest that, although the proportion of resistant strains in the London population has not increased during the past 2 years, it is possible that the standard dosage of penicillin is still too low and that some strains may persist, become resistant, and not only cause relapse but even become disseminated.

The almost complete failure of treatment of the disease in eleven patients comprising 15.3 per cent. of all cases of gonorrhoea described by Mead, Moon, and Bean (1960) in the U.S. army over a period of 6 months in spite of treatment with four injections of 600,000 units penicillin would certainly suggest this.

\section{Summary}

The sensitivity to penicillin of strains of gonococci from 107 patients was tested in 1960; 91 per cent. were sensitive and 9 per cent. insensitive. The recurrence rate amongst 92 patients with sensitive strains was 13 per cent., against 38 per cent. amongst eight patients with insensitive strains. The incidence of relative resistance to penicillin in vitro has fallen from 19 per cent. in 1958 to 10 per cent. in 1960 . This difference can be accounted for by the higher dosage of penicillin used in 1960 which probably eliminated some strains which may have previously become resistant.

We should like to thank Professor R. Hare for helpful criticism and advice.

\section{REFERENCES}

Cradock-Watson, J. E., Shooter, R. A., and Nicol, C. S. Brit. med. J., (1958), 1, 1091.

Mead, R. K., Moon, N. F., and Bean, L. L. (1960). U.S. armed Forces med.J., 11, 1117.

Comparaison de la sensibilité à la pénicilline de $N$. gonorrhoeae, 1960 et 1958

\section{Résumé}

La sensibilité à la pénicilline de souches de gonocoques de 107 malades fut vérifiée en 1960; $91 \%$ étaient sensibles et $9 \%$ étaient insensibles. Le taux de récidive chez 92 malades ayant des souches sensibles était de $13 \%$, contre $38 \%$ chez les 8 malades ayant des souches insensibles. L'incidence de la résistance relative à la pénicilline in vitro est tombée de $19 \%$ en 1958 à $10 \%$ en 1960. Cette différence peut s'expliquer par le dosage plus élevé employé en 1960, ce qui a probablement éliminé certaines souches qui autrefois seraient devenues résistantes. 